\title{
Investigation of Learning Behaviors and Achievement of Simple Pendulum for Vocational High School Students with Ubiquitous- Physics App
}

\author{
Siska Wati Dewi Purba ${ }^{1}$, Wu-Yuin Hwang ${ }^{1 *}$ \\ ${ }^{1}$ Graduate Institute of Network Learning Technology, National Central University, Jhongli City, TAIWAN
}

Received 11 September 2017 - Revised 18 April 2018 • Accepted 21 April 2018

\begin{abstract}
In this study, Ubiquitous-Physics was designed and proposed for facilitating students to learn simple pendulum concepts. U-Physics can facilitate collecting experimental data and drawing the corresponding graphs during the experiment, whereby students can focus on how to interpret graphs and solve problems through applying formulas. The participants were second grade female vocational high school students who are fewer interests in physics, while hopefully using U-Physics in the physical experiment can motivate their interests and help their learning in physics. The findings showed that significant correlations existed among hypothesis-making, interpreting graphs, applying formulas, conclusion-making, conceptual understanding, and post-test. After an in-depth investigation, we found that interpreting graphs and conceptual understanding were the two most important factors to affect learning achievement. Additionally, students perceived that U-Physics was beneficial to their physics learning.
\end{abstract}

Keywords: applying formulas, conceptual understanding, hypothesis-making, interpreting graphs, Ubiquitous Physics (U-Physics)

\section{INTRODUCTION}

Learners need to use critical thinking to create great articulations and summary on explaining their answers when they learn physics. In practices, learners not only need to understand physics principle and calculation but also cultivate how to improve crucial thinking and reasoning adequately. Representation abilities of learners' were shown to help critical thinking and problem solving (Leslie, Low, Jin, \& Sweller, 2012; Mayer, 1992; Nievelstein, Van Gog, Van Dijck, \& Boshuizen, 2013; Stylianou \& Silver, 2004; Sullivan \& Puntambekar, 2015). Learners need to explore and discover unique examples or principles inside the issues, and then utilize representations to clarify comparable issues with different structures or viewpoints in the process of applying formulas. Regardless, a few studies claimed that most learners neglect to understand the essentialness of relationship between different types of representations (Ainsworth, 1999; Kalyuga, Chandler, \& Sweller, 2000).

A successful of physics learning cannot be separated from students' learning behaviors while they are doing physics experiment. Teachers can study students' learning behaviors to know whether students pay attention, understand concepts and procedural instructions and measure the results of the experiment. Making hypothesis/assumptions is an important aspect of the testing experiment and a vital step in solving daily physics phenomena and need to be developed to support students' physics learning (Etkina, Murthy, \& Zou, 2006; Fortus, 2009). Hypothesis-making is students' prediction before experimenting. We assumed that hypothesis-making would affect students' learning achievement.

Graphs could be utilized to help physics and mathematics learning (Supalo, Humphrey, Mallouk, Wohlers, \& Carlsen, 2016; Zebehazy \& Wilton, 2014). The ability to interpret, recognize, understand, and work with graphs involves mathematical skills and processes (Friel, Curcio, \& Bright, 2001). This ability called interpreting graphs knowledge which can be very helpful before, during, and after physics experiment. However, recently, information

(c) 2018 by the authors; licensee Modestum Ltd., UK. This article is an open access article distributed under the terms and conditions of the Creative Commons Attribution License (http://creativecommons.org/licenses/by/4.0/).

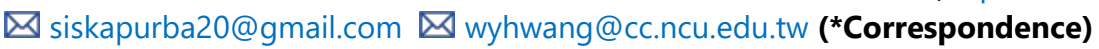




\section{Contribution of this paper to the literature}

- Interpreting graphs played a critical role in a physics experiment, so we strongly suggest experimental procedure should ask learners to interpret physics phenomena by graphs.

- U-Physics is not only an excellent tool to measure the period of pendulum more accurately by providing interpreting graphs rather than a traditional tool but also can link students' concept and experiment measurement in a lab.

- U-Physics using the sensors of Tablet PC's with multi-representation can facilitate teachers and students not only to build physics phenomena but also to organize and manipulate sampling data for in-depth analysis.

or content of knowledge is not often expressed using graph representations and pictures in mathematics, engineering and science (Zebehazy \& Wilton, 2014).

In a physics experiment, applying formulas and calculation processes are a part of physics language. The mathematical expression and processes are used to incorporate or deliver critical components of content; most physicists read a formula in composed writings and expressed it into physical notions. The ability to apply and calculate formulas in physics learning can improve students' concepts and knowledge through applying what they discovered in authentic context as well as scientifically communicating with others (Lin, Liang, \& Tsai, 2015). It is essential for students not only to comprehend physical and mathematical concepts independently but also understand the correlation between physical and mathematical for active learning (Greca \& de Ataíde, 2017).

Students must conclude and decide to reject or accept hypotheses from data gathered (De Jong, 2006) after experimenting. This conclusion-making is students' ability to conclude their experiment result, and it might be helpful for constructing or reconstructing their hypothesis.

Based on above mentioned, we considered that these five students' behaviors included hypothesis-making, interpreting graphs, applying formulas, conclusion-making, and conceptual understanding is associated with students' learning achievement. Therefore, we experimented with vocational high school students and designed a U-Physics mobile app to facilitate students learn simple pendulum concepts. Besides, we studied the five learning behaviors and its relation to learning achievement. This study also investigated students' perception towards UPhysics app in learning simple pendulum for helping the further improvement of our activity and app designs.

\section{LITERATURE REVIEW}

\section{Representation to Facilitate Scientific Learning}

Representations have various meanings. For instance, it can be a configuration of concrete objects, images, or character which can represent something else (DeWindt-King \& Goldin, 2003). Arithmetic, language, and graph belong to representation (Hwang, Chen, Dung, \& Yang, 2007). Commonly, arithmetic symbol, language, authentic object, concrete, and graphic representations are used in Mathematics learning (Lesh, Post, \& Behr, 1987). The language, arithmetic symbol, and graphics are the most important and abstract for mathematical problem solving (Lesh et al., 1987; Milrad, 2002; Zhang, 1997).

Students with good problem-solving skills are those who are also good at manipulating and using language, graphs, and arithmetic representations. In contrast, students with low problem-solving skills are difficult to represent and translate an observed object. Therefore, teachers should acquire various teaching strategies to encourage students to use multi-representation in class, and learning achievement should then be enhanced (Cai \& Hwang, 2002).

The correct use of representation is crucial and considered a key to physics learning. Students' representation abilities in physics learning can help teachers to understand how well their students interpret and solve physics phenomena. Besides, teachers also can know whether students understand physics concepts profoundly or not through their representation skills (Kohl, Rosengrant, \& Finkelstein, 2007). So in this study, we would ask students to use various representations to learn simple pendulum. Students need to find some clues to solve related physics problems with hypothesis making, applying formulas, and graphs explaining supported by U-Physics.

\section{Authentic Learning}

A familiar authentic surrounding creates advantages to help comprehension and application of new cognition. A study demonstrated that daily life problems in the authentic scenario were related to language acquisition (Hwang, Chen, Shadiev, Huang, \& Chen, 2014). The authentic context is a critical prerequisite for active learning (Kiernan \& Aizawa, 2004). Authentic learning can provide contexts that reflect the way in which the knowledge will be used in real life and promote reflection. Authentic learning also should provide activities that have daily 
life relevance and offer authentic within-task learning assessment. Furthermore, authentic context should be able to create a chance for learners to share learning experiences and enables learners with different levels of expertise to practice (Hwang, Huang, Shadiev, Wu, \& Chen, 2014).

A study claimed that authentic environment was useful for learning (Hwang, Chen, et al., 2014). It is similar with the cultural schema theory (Nishida, 2005), which mentioned that the knowledge and pre-knowledge together arise when observing familiar authentic environments. The study also argued that the schema was created based on the information from our environment and saved it in the brain. The environment becomes familiar after we enter repeatedly. The saved schema guides and helps us to predict what is to be expected and looked for in a familiar environment.

One of the advantages of mobile technology in learning is to offer seamless learning. Mobile technology can be used anytime and anywhere to facilitate students' learning (Kim, Suh, \& Song, 2015). It may also create an authentic learning environment within a familiar context rich in resources for learning (Kim \& Kim, 2012). Furthermore, mobile technology can be used for formal and informal learning (Wang, Wu, \& Hsu, 2017).

Multimedia such as image, audio, and text generated by learners through mobile technology can make learning more meaningful and interesting, particularly using media in an authentic environment. The use of image and audio in authentic contexts can also make learning more interactive, productive and engaging (Golonka, Bowles, Frank, Richardson, \& Freynik, 2014). In addition, studies shown that multimedia such as graphs and text annotations and the sensor technology of mobile devices could help students in exploring and applying their knowledge through laboratory activities (Purba \& Hwang, 2017a, 2017b).

\section{Learning Behaviors in Scientific Learning}

Learning is a process of relatively permanent change in behaviors created by experience and practice in an environment. A study demonstrated that general knowledge and behavioral were critical indicators of students' learning achievement (McLeod \& Kaiser, 2004). The education literature also indicated that students' learning behaviors influenced the learning process. For instance, one of the ways to promote a more informal approach to students' learning behaviors is to utilize a social media such as Line, Facebook, and so on during their learning process (Dabbagh \& Kitsantas, 2012).

Students' learning behaviors in physics can help teachers to know whether students focus, understand concepts, are aware of procedural instructions and measure the proper outcome of an experiment. Students learning can be improved by providing learning guidance and instruction after we analyzed students' behaviors.

\section{Hypothesis-making}

Hypothesis making is an essential step in solving daily physics phenomena and needs to be developed to support students' physics learning (Fortus, 2009). The hypothesis is a tentative specification of the effect of the input variables on the output variables. The hypothesis is can also have the form of a model or part of the model (De Jong, 2006). There are two approaches to generate a hypothesis; one is from theory, and the other is from data (from running experiments) (Klahr \& Dunbar, 1988). The hypothesis could be an explanation of a pattern within the data and an exploration of relationship between variables (Etkina et al., 2006). Hypothesizing an experiment is one of the crucial factors of designing a test experiment. At the end of their experiment process, students have to accept or reject their hypothesis based on their findings.

\section{Interpreting graphs}

A study stated that graphs and its interpretations are the heart of science. Interpreting graphs are very crucial because it is a part of experimentation (McKenzie \& Padilla, 1986). The interpreting ability is an essential requirement for expertise in problem-solving (Larkin \& Reif, 1979). Researchers showed that graphs could be utilized to help physics and mathematics learning (Supalo et al., 2016; Zebehazy \& Wilton, 2014). The ability to interpret, recognize, and work with graphs involves mathematical skill and processes (Friel et al., 2001). It can be useful in experiment process. Students can extract most of their information content using graphs (Beichner, 1994). Besides, interpreting graphs can help improve better conceptual understanding (Lingefjärd \& Farahani, 2017). However, information or content of knowledge is not often expressed using graph representations and pictures in mathematics, engineering and also science (Zebehazy \& Wilton, 2014). Therefore, in this study, we encouraged students to interpret graph based on their experiment findings through our developed app, U-Physics. 


\section{Applying formulas}

Physics language cannot be isolated from mathematical expression. The mathematical expression and processes are used to incorporate or deliver critical components of content; most physicists read a formula in a composed writings and expressed it into physical notions. The ability to apply and calculate formulas in physics learning can improve students' concepts and knowledge through applying what they discovered in authentic contexts as well as scientifically communicating with others (Lin et al., 2015). The understanding of utilizing of physics formulas can significantly express students' concepts of the learning materials (Sherin, 2001). The arrangement of symbols in physics formulas represent a meaning that can be understood by learners. Students understanding of what the formulas say in essential meanings could lead and guide their works. In this study, we ask students not only to use symbolic expressions but also understand the meaning of symbolic expressions and its manipulations.

\section{Conclusion-making}

Conclusion-making is students' ability to conclude their experiment result, and it might be helpful for constructing or reconstructing their hypothesis. In a physics experiment, learners must conclude and decide to reject or accept hypotheses from data gathered (De Jong, 2006). In other words, after doing experiment students need to conclude what they found from data gathered. This conclusion is a way to confirm their previous hypothesis. It shows that hypothesis-making correlated to conclusion-making.

\section{Conceptual understanding}

Conceptual understanding of physics is necessary for learning and becomes a critical part of solving problems related to physics phenomena. It is crucial for students to understand not only physics concepts and mathematics concepts separately but also relationships between physics and mathematics concepts in creating efficient learning (Greca \& de Ataíde, 2017). Besides, Conceptual understanding is students' ability to summarize and construct or reconstruct their concept of learning material. To lead students' conceptual understanding effective physics instruction must encourage the kind of learning. Many researchers claimed that an experience that leads students to evaluate their conception and be encouraged to develop a better replacement on their perspective could build students' scientific conception (Duschl \& Gitomer, 1991; Dykstra, Boyle, \& Monarch, 1992; Posner, Strike, Hewson, \& Gertzog, 1982). In this study, conceptual understanding is students' thinking and ideas about the meaning and content of science concepts. Students' conceptual understanding could be promoted by allowing students to explore science phenomena with a computer or mobile app in their surroundings (Lee, Nicoll, \& Brooks, 2004; McElhaney, Chang, Chiu, \& Linn, 2015; Wang et al., 2017).

Based on above mentioned, we considered that these five students' behaviors included hypothesis-making, interpreting graphs, applying formulas, conclusion-making, and conceptual understanding is associated with students' learning achievement.

\section{UBIQUITOUS-PHYSICS (U-PHYSICS)}

We developed a Ubiquitous-Physics (U-Physics) mobile app to help and facilitate students learn simple pendulum concepts in physics class. The U-Physics app works on tablet PC or smartphones. The app utilized an acceleration sensor of the tablet to collect acceleration and velocity values. Those values are transformed into a graph and used to facilitate students' understanding of the pendulum period time. In the current study, we focused on three different experiment about the simple pendulum. The first experiment aims to help students learn the effect of pendulums' mass concerning it swing period. The second experiment aims to help students learn the effect of pendulums' length concerning it swing period. The last experiment is to help students learn the effect of pendulums' angle or inclination concerning it swing period. Three different leading questions and learning materials were installed in U-Physics. In addition, U-Physics also provides annotation function to help students interpret and explain their understanding of simple pendulum concepts easily.

Three main functions work in U-Physics. The first function is a general function. This function aims to start, stop, open the leading questions, screenshot a graph, and open the gallery files. Those are shown in button 1, 2, 9, 10, and 15 of Figure 1, respectively. The second function is interpreting graphs function. This function is to show several graphs based on different axes and values. Acceleration sensor inside the tablet collects those graphs values. The button function is shown in button three until button 8 . Students were asked to select one of the graphs and interpret it. The last function is annotation function and shown in button 11 to 14 (Figure 1 and 2). Studied can edit their graphs functions in button 11 to 13 after experimenting. Then students need to complete their results by writing and putting the evidence and conclusions in function 14 layout. 


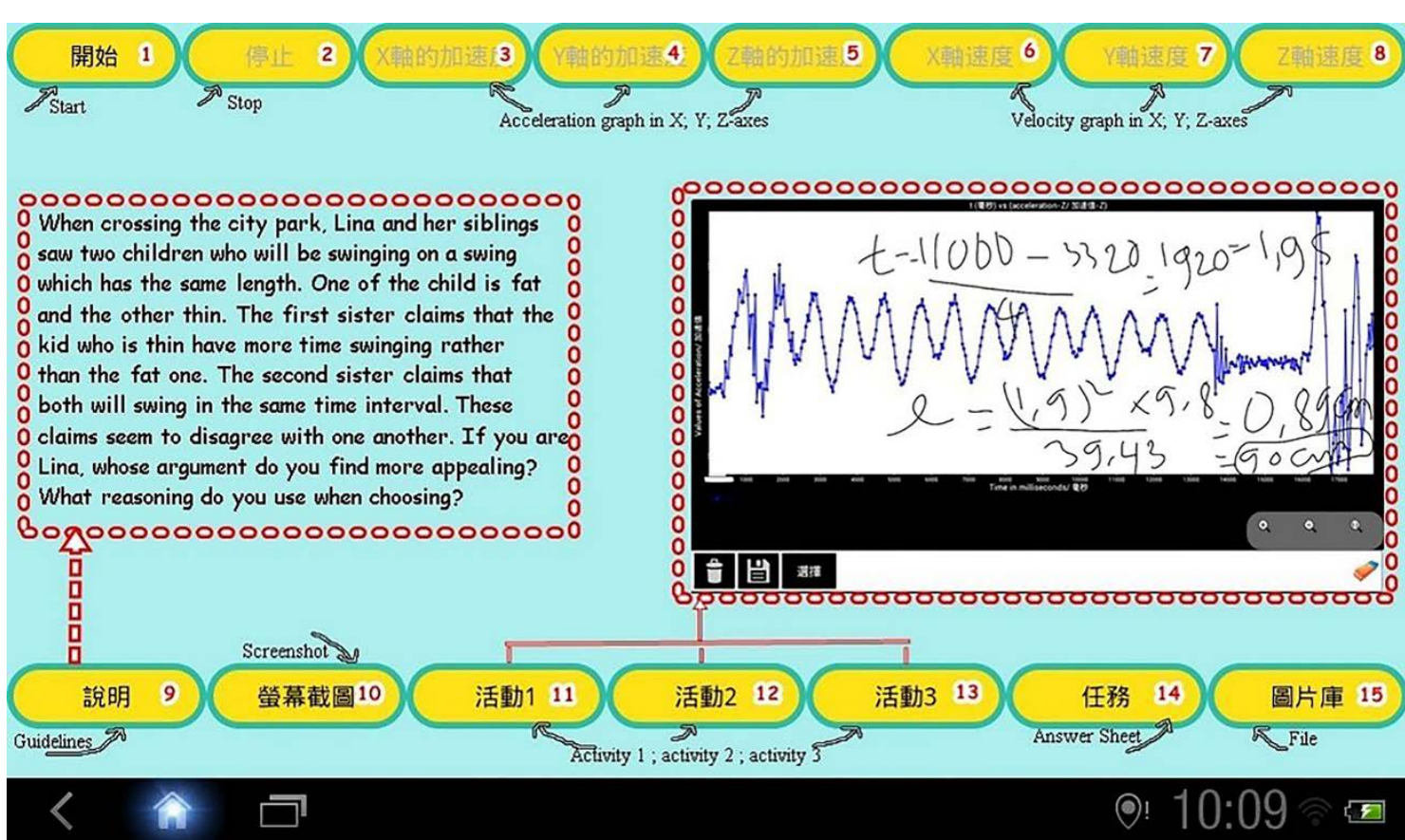

Figure 1. U-Physics user interface including guidelines and activities

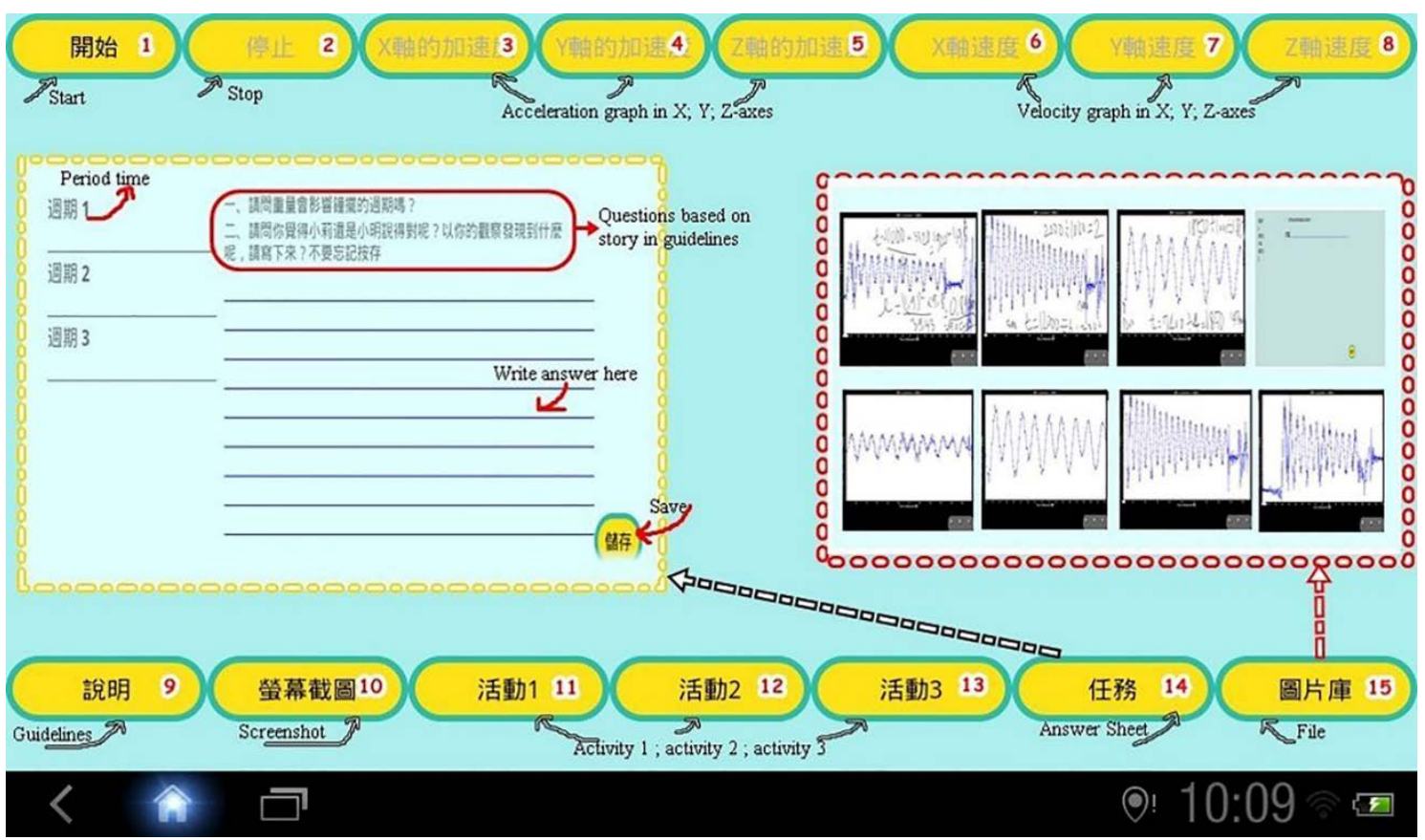

Figure 2. U-Physics user interface including answer sheet and file

\section{METHODOLOGY}

\section{Participant}

Sixty-six female students of the second-grade vocational high school participated in the experiment. Their ages were around sixteen to seventeen. Moreover their major is related to applied science, so they seldom do such kind of physics experiment during their vocational high school study. An experienced physics teacher taught the two groups with the same learning material about simple pendulum concept. The learning materials of the two groups were designed based on a school textbook. In this study, there were three different experiment we were conducted: (1) different mass; (2) different length; and (3) different angle. Demographic results also showed that most of the 
Table 1. Learning behaviors and learning achievement marking criteria

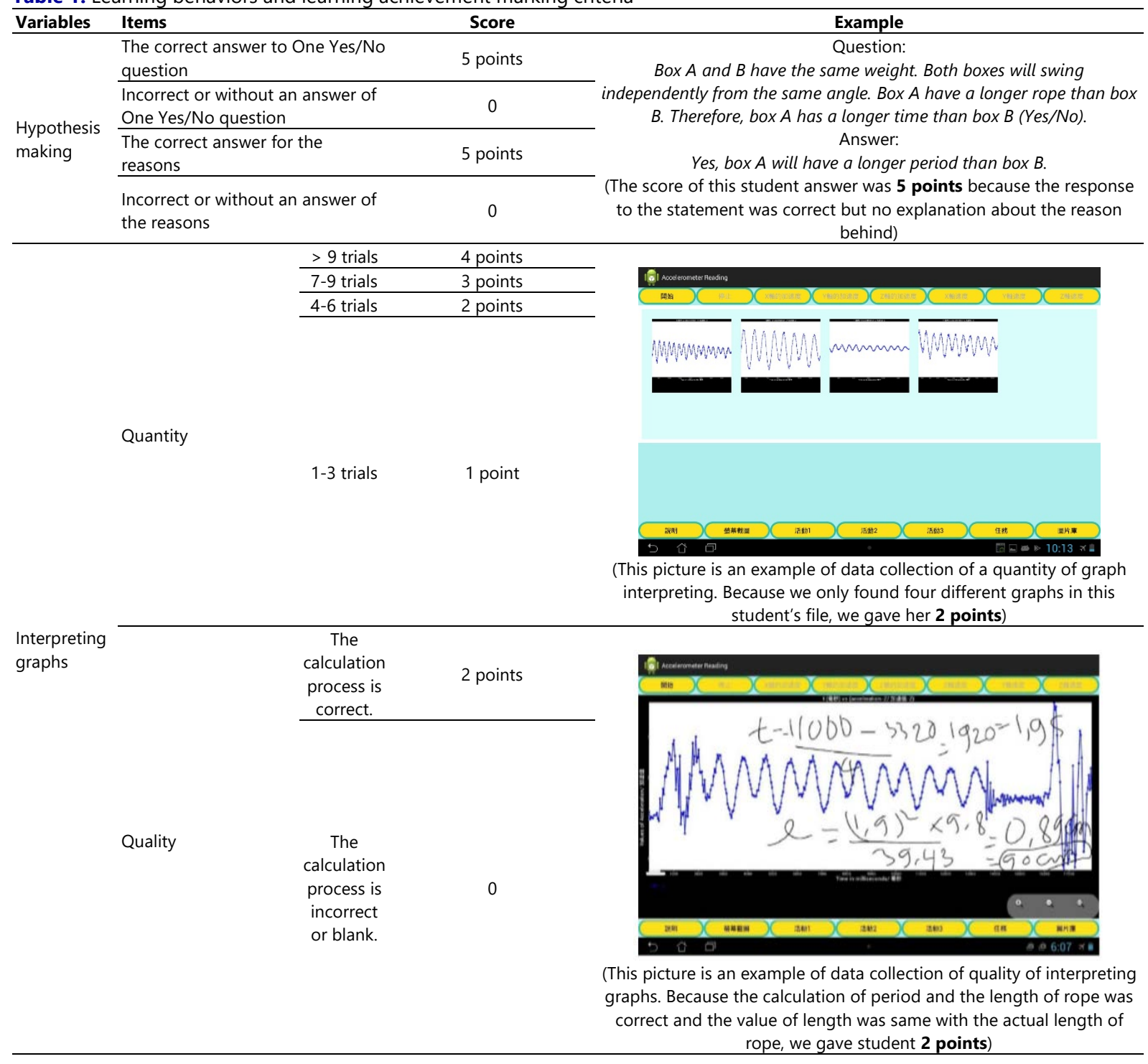

students (55 students) have fewer interests in learning physics because physics is not their major. Experimental class $(\mathrm{N}=32)$ and control class $(\mathrm{N}=34)$ were randomly divided into pairs, respectively. Each pair in experimental class used our proposed app, U-Physics, in tablet PC. While in control class, each pair had a stopwatch app on their smartphone/ tablet PC.

\section{Purpose}

We aimed to study the five learning behaviors and their relation to learning achievement of vocational students. Three research questions are specified as follows:

1) Does experimental group perform better than a control group on learning achievement?

2) What is the relationship among learning behaviors variables such as hypothesis-making, interpreting graphs, applying formulas, conclusion-making, conceptual understanding and their effects on learning achievement (Post-test)?

3) What is students' perception of U-Physics app?

Hypothesis-making, interpreting graphs, applying formulas, conclusion-making, and conceptual understanding belong to learning behaviors factors. The post-test belongs to learning achievement factor. An experienced Physics teacher evaluated the marking criteria. Table 1 shows the marking criteria of each variable and its definition as described below: 
Table 1 (continued). Learning behaviors and learning achievement marking criteria

\begin{tabular}{|c|c|c|c|c|}
\hline Variables & & Items & Score & Example \\
\hline \multirow{8}{*}{$\begin{array}{l}\text { Applying } \\
\text { formulas }\end{array}$} & \multirow{2}{*}{ Item 1} & $\begin{array}{l}\text { The calculation process } \\
\text { is correct. }\end{array}$ & 5 points & \\
\hline & & $\begin{array}{l}\text { The calculation process } \\
\text { is incorrect or blank. }\end{array}$ & 0 & \\
\hline & \multirow{2}{*}{ Item 2} & $\begin{array}{l}\text { The calculation process } \\
\text { is correct. }\end{array}$ & 5 points & \\
\hline & & $\begin{array}{l}\text { The calculation process } \\
\text { is incorrect or blank. }\end{array}$ & 0 & 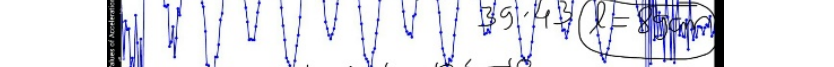 \\
\hline & \multirow{2}{*}{ Item 3} & $\begin{array}{l}\text { The calculation process } \\
\text { is correct. }\end{array}$ & 5 points & $A 11 B 2 C 3 C$ \\
\hline & & $\begin{array}{l}\text { The calculation process } \\
\text { is incorrect or blank. }\end{array}$ & 0 & 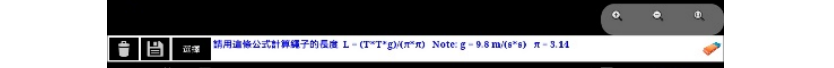 \\
\hline & \multirow{2}{*}{ Item 4} & $\begin{array}{l}\text { The calculation process } \\
\text { is correct. }\end{array}$ & 5 points & (We picked up an example of applying formulas as the picture above. \\
\hline & & $\begin{array}{l}\text { The calculation process } \\
\text { is incorrect or blank. }\end{array}$ & 0 & applying formulas, there were four items entirely) \\
\hline \multirow{4}{*}{$\begin{array}{l}\text { Conclusion } \\
\text { making }\end{array}$} & \multicolumn{2}{|c|}{$\begin{array}{l}\text { The correct answer to One Yes/No } \\
\text { question }\end{array}$} & 5 points & $\begin{array}{l}\text { Question: } \\
\text { Box } A \text { and } B \text { have the same weight. Both boxes will swing independently from }\end{array}$ \\
\hline & \multicolumn{2}{|c|}{$\begin{array}{l}\text { Incorrect or without an answer of } \\
\text { One Yes/No question }\end{array}$} & 0 & $\begin{array}{c}\text { the same angle. Box } A \text { have a longer rope than box } B . \text { Therefore, box } A \text { has a } \\
\text { longer time than box } B(Y e s / N o) .\end{array}$ \\
\hline & \multicolumn{2}{|c|}{ The correct answer for the reasons } & 5 points & Answer: \\
\hline & \multicolumn{2}{|c|}{$\begin{array}{l}\text { Incorrect or without an answer of the } \\
\text { reasons }\end{array}$} & 0 & $\begin{array}{l}\text { Yes, box } A \text { will have a longer period than box } B \text {. This is because box } A \text { has a } \\
\text { longer rope than box } B \text {. The period is proportional to the length of the rope. } \\
\text { (The score of this student answer was } \mathbf{1 0} \text { points because the response to the } \\
\text { statement was correct as well as the reason) }\end{array}$ \\
\hline \multirow{8}{*}{$\begin{array}{l}\text { Conceptual } \\
\text { understanding }\end{array}$} & \multirow{2}{*}{$\begin{array}{l}\text { Write down } \\
\text { simple } \\
\text { pendulum } \\
\text { formula }\end{array}$} & Correct & 2 points & \\
\hline & & Incorrect & 0 & 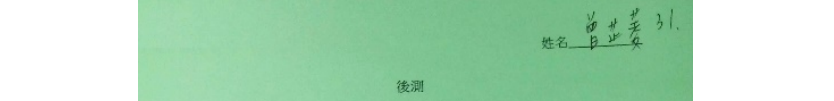 \\
\hline & \multirow{6}{*}{$\begin{array}{l}\text { Explanation } \\
\text { of simple } \\
\text { pendulum } \\
\text { formula }\end{array}$} & $\begin{array}{l}\text { The correct definition } \\
\text { of Simple pendulum } \\
\text { variables only }\end{array}$ & 2 points & The understanding test \\
\hline & & $\begin{array}{l}\text { The incorrect or } \\
\text { without a definition of } \\
\text { Simple pendulum } \\
\text { variables only }\end{array}$ & 0 & $\begin{array}{l}\text { Please write down simple pendulum's formula! (20 points) } \\
\qquad T=2 \pi \sqrt{\frac{l}{g}}\end{array}$ \\
\hline & & $\begin{array}{l}\text { The correct correlation } \\
\text { among simple } \\
\text { pendulum variables }\end{array}$ & 3 points & 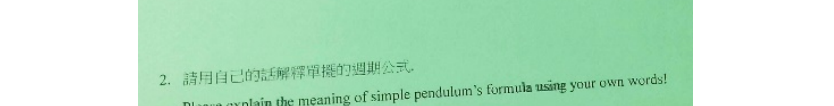 \\
\hline & & $\begin{array}{l}\text { The incorrect or } \\
\text { without correlation } \\
\text { among simple } \\
\text { pendulum variables }\end{array}$ & 0 & 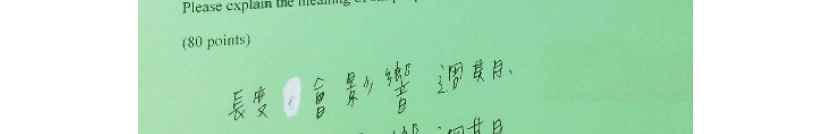 \\
\hline & & $\begin{array}{l}\text { The correct examples to } \\
\text { support the definition }\end{array}$ & 3 points & 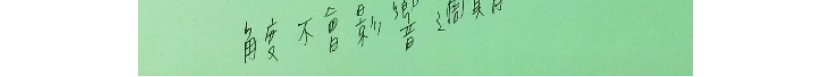 \\
\hline & & $\begin{array}{l}\text { The incorrect or } \\
\text { without examples to } \\
\text { support the definition }\end{array}$ & 0 & $\begin{array}{l}\text { (The first question, her answer was correct, so we gave } \mathbf{2} \text { points. The second } \\
\text { question, her response is the period of pendulum only depends on the } \\
\text { length of the pendulum. The other factors such as the angle and weight of } \\
\text { pendulum will not affect the period. These statements are correct, so we } \\
\text { gave } \mathbf{3} \text { points. So the total score of conceptual understanding for her was } \mathbf{5} \\
\text { points.) }\end{array}$ \\
\hline \multirow[t]{2}{*}{ Pre-test } & \multirow[t]{2}{*}{$\begin{array}{l}8 \text { Multiple } \\
\text { choice } \\
\text { questions }\end{array}$} & Correct & $\begin{array}{l}5 \text { points/ } \\
\text { each item } \\
\text { (The total } \\
\text { score for } \\
\text { multiple } \\
\text { choice is } 40 \\
\text { points) }\end{array}$ & \multirow[t]{2}{*}{ For the example of pretest and posttest please refers to Figure 3.} \\
\hline & & Incorrect/blank answer & 0 & \\
\hline \multirow[t]{2}{*}{ Post test } & \multirow{2}{*}{$\begin{array}{l}1 \text { Essay } \\
\text { question }\end{array}$} & \multirow{2}{*}{$\begin{array}{l}\text { There were three } \\
\text { answers to the essay. } \\
\text { Each answer will get } 20 \\
\text { points, and the total } \\
\text { score for the essay is } 60 \\
\text { points. }\end{array}$} & Correct & $\begin{array}{c}20 \\
\text { points/ } \\
\text { answer }\end{array}$ \\
\hline & & & $\begin{array}{c}\text { In } \\
\text { correct/blank } \\
\text { answer }\end{array}$ & 0 \\
\hline
\end{tabular}


Hypothesis making is students' ability to predict the possibility of experiments' results before an experiment. Each experiment has the questions of hypothesis-making. If the answer and reason are correct, we gave 10 points. If students only have the right answer or reason, we gave 5 points. We gave 0 point if students' answer and reason are incorrect. . We gave the equal points for a correct answer and reason because the physics teacher and researchers thought we should appreciate equally their efforts to answer this question no matter it was guessed only. Since they are seldom done physics experiments in vocational high school, and their majors are not science, so we decided to give 5 points equally for a correct answer and reason.

Interpreting graphs are students' ability to interpret their graphs and find the period correctly. The interpreting graphs were evaluated into two aspects, quantity and quality. The different mass, length, and angle were divided into three kinds of mass (the first mass, the second mass, and the third mass); length (the first length, the second length, and the third length); and angle (the first angle, the second angle, and the third angle) respectively. So there are nine sub-experiments in total. In each sub-experiment students should experiment in three times. It means every time students experiment they collect graphs as well. The quantity of interpreting graphs were evaluated based on how many times they do an experiment and collect the graphs. Each graph has one point. In summary, students can get nine points totally for nine times doing sub-experiment in an experiment. In case students are diligent and do the experiment more than nine times, we gave them extra points. We appreciated the students' efforts to repeat the experiment more than our expectation to sharpen their understanding of the topic. The quality of interpreting graphs were evaluated based on the interpreting process and annotation in the graphs. The maximum scores are six points in an experiment. For example, different length experiment divided into the first length, second length, and third lengths. The first length experiment would have two points if students marked and selected period correctly as well as the second and third length experiments.

Applying formulas are the ability to use a formula and calculate the length of the period time. The maximum scores are twenty points in an experiment. Students were asked to select four graphs out of their findings and calculate it. For example, concerning the different length experiment, we gave five points for a graph, if students calculated the period time and the length of rope correctly.

Conclusion making is students' ability to conclude the experiment result. Conclusion making is a way to reject or accept their previous hypothesis making based on the gathered data. Conclusion making criteria are similar to hypothesis making ones.

Conceptual understanding is students' ability to summarize and construct or reconstruct their concept of learning material. In this study, we used one conceptual test to measure their conceptual understanding of the simple pendulum phenomenon. Researcher and teacher developed and designed the test content together. We gave this test to students at the end of all experiments. The conceptual understanding criteria divided into two questions. The first question is to write down a simple pendulum formula, and the correct formula has two points. The second question is to explain the meaning of the formula. If students wrote the explanation of formula's variables correctly, they got two points. If students wrote the correlation among the formula's variables correctly, they got three points. Moreover, if students wrote the example of a simple formula to support their definition successfully, they got three points more. So there are ten points in total for conceptual understanding.

Pre-test had eight multiple choice questions and one open-ended question as well as in post-test. The correct answer to each multiple choice is five points, and the correct answer to an open-ended question is sixty points. The open-ended question has three answers; therefore each answer has twenty points. In summary, the maximum scores of pre-test are a hundred points as well as in post-test.

\section{Instrument and Tool}

\section{Pre-test and post-test}

We asked students to complete eight multiple choice questions and an open-ended question in the pre-test and post-test section. The questions related to their learning activities such as hypothesis-making, interpreting graphs, applying formulas, conclusion-making, and conceptual understanding. Both tests are similar to each other (Figure 3). 
Pretest Example

1. Suppose the pendulum experiment pendulum weighs $500 \mathrm{grams}$, the angle is equal to $10^{\circ}$ and period is equal to 3 seconds. The pendulum weight will replace to 200 grams, how is the period? (5 points)

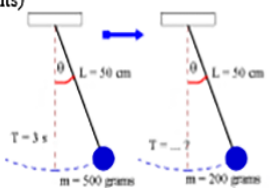

a. 0.6

b. 25
c. $35^{*}$

c. $3 \mathrm{~s}^{*}$

2. Assume that the pendulum experiment, the angle is equal to $30^{\circ}$ to the measurement period is 1.7 seconds and has the same length. How is the period if the angle change to $60^{\circ}$ ? ( 5 points)

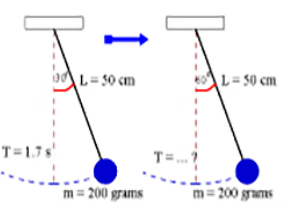

a. $2 \mathrm{~s}$

b. 1.45

c. $1.7 \mathrm{~s}^{*}$
d. $3 \mathrm{~s}$

Figure 3. Pre-test and post-test example
Posttest Example

1. Suppose the pendulum experiment pendulum length of $50 \mathrm{~cm}$, the angle equal to $10^{\circ}$ of a pendulum with a period of 1.4 seconds. The length will replace to $20 \mathrm{~cm}$, how is the period? (5 points)

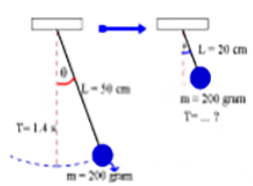

a. $0.6 \mathrm{~s}^{8}$

b. $1.4 \mathrm{~s}$

c. $2.0 \mathrm{~s}$

d. 7.0

2. Assume that the pendulum experiment, the angle is equal to $30^{\circ}$ to the measurement period is 1.7 seconds and has the same length. How is the period if the angle change to $45^{\circ}$ ? (5 points)

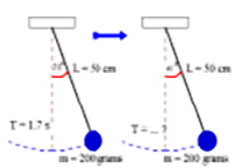

25

b. $1.4 \mathrm{~s}$
c. $1.7 \mathrm{~s}^{*}$

d. $3 \mathrm{~s}$

\section{TAM questionnaire}

Technology Acceptance Model (TAM) was originated by Davis in 1989 to explain and predict the individual's acceptance of information technology (IT). TAM is extensively applied to investigate how attitudes and beliefs toward using specific information app influencing the behavioral intention and therefore actual app use. As new types of cyber medium rapidly emerged, TAM has been validated by many researchers and has become a robust theoretical model.

Students' perception towards U-Physics were evaluated by collecting TAM questionnaire responses. TAM divided into four dimensions: (1) perceived ease of use; (2) perceived usefulness; (3) intention to use; and (4) students' attitude of an app (Chung \& Tan, 2004). Many researchers have employed the TAM questionnaire in their studies (Hwang, Huang, et al., 2014; Purba \& Hwang, 2017a, 2017b). Therefore, we used these four dimensions and generated into fourteen questionnaire items with a seven-point Likers scale. We interviewed six students randomly to support our findings.

\section{Material and procedure}

We used U-Physics app to help students learn and understand a period of the simple pendulum. Three different experiments were conducted in this study. The first experiment aims to learn the effect of pendulums' mass concerning its swing period. We asked students to swing three different masses, a tablet, two tablets, and three tablets, respectively. Students swing and stop it after swinging back and forth seven times. Then they study their saved graph generated by U-Physics. We expected students could conclude a right conclusion and understand that mass would not affect the period time of simple pendulum at the end of the experiment. The second experiment aims to learn the effect of pendulums' length concerning its swing period. Students were asked to change three different lengths, $40 \mathrm{~cm}, 70 \mathrm{~cm}$, and $90 \mathrm{~cm}$, respectively. We expected students could conclude a right conclusion and understand that length would affect the period time of simple pendulum at the end of the experiment. The last experiment is to learn the effect of pendulums' angle or inclination concerning its swing period. Students were asked to change three different angles, 15 degrees, 30 degrees, and 45 degrees, respectively. We expected students could conclude a right conclusion and understand that angle is less than or equal to 15 degrees would not affect the period time of the simple pendulum and angle is greater than 15 degrees would affect the period time of the simple pendulum.

In each experiment, there were several tasks need to complete. For instance, hypothesis-making, collecting and interpreting graphs, applying formulas, conclusion-making, and conceptual understanding test. The overall research procedures were presented in Figure 4. 

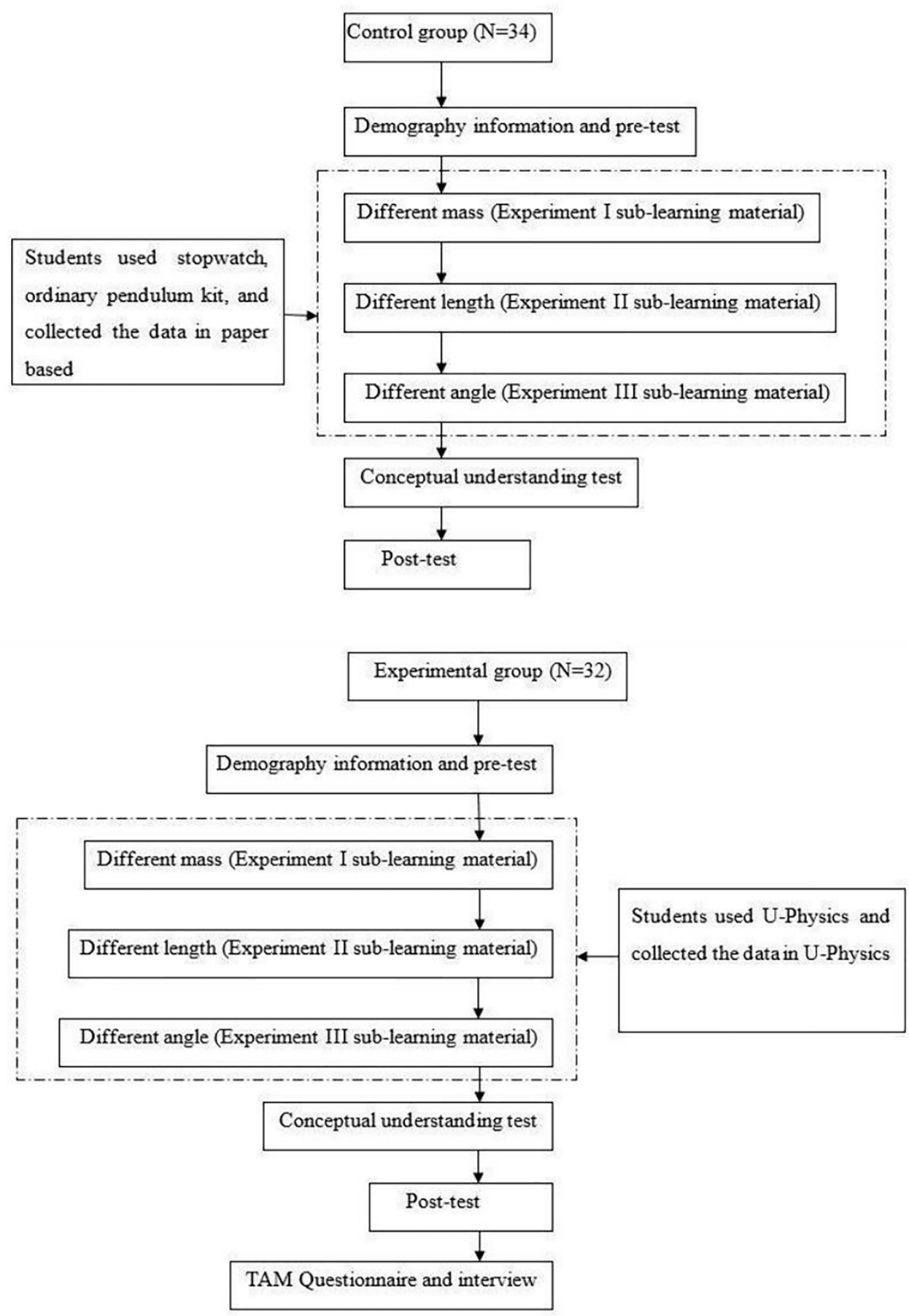

Figure 4. Research procedure

Doing a simple pendulum experiment for three weeks and remains for collecting demographic information, pre-test, conceptual understanding, post-test, questionnaire, an interview. Students were given an hour to complete experiment activities at each meeting. We randomly selected eight experimental group students to take the interview. The interview questions were described as below:

1. Did you interact with your partner during experiment activity?

2. Which part of experimental activity did you spend more time than others?

3. How did you solve the problem if you have different opinions with your partner during the experimental activity?

4. Did you understand the meaning of the formula and how to use it? 
Table 2. The result of the pre-test and post-test and analysis of independent samples

\begin{tabular}{lcccccccc}
\hline \multirow{2}{*}{ Groups } & \multicolumn{4}{c}{ Pretest } & \multicolumn{3}{c}{ Post-test } \\
\cline { 2 - 10 } & \multicolumn{3}{c}{ Independent samples test } & \multicolumn{3}{c}{ Independent samples test } \\
\cline { 2 - 10 } & Mean & SD & t & Sig.(2-tailed) & Mean & SD & t & Sig.(2-tailed) \\
\hline Control & 35.88 & 13.51 & & & & 41.47 & 22.44 & \\
\hline Experiment & 35.93 & 11.87 & 0.18 & 0.986 & 76.87 & 14.90 & 7.49 & $<0.001$ \\
\hline
\end{tabular}

5. Did you think an hour is enough for you to conduct the experiment and learn the simple pendulum phenomena?

6. If the teacher allows you to bring the tablet back, what will you do?

\section{Data Analysis}

In this study, Pearson correlation was employed to explore relationships between students learning behaviors and learning achievement. A t-test was used to analyze comparison between students' post-test and pre-test in both groups. Finally, we used means comparison for analyzing of TAM questionnaire.

\section{RESULTS AND DISCUSSION}

The results and discussion were divided into three sections. The first section is to show and discuss any difference between students who used the U-Physics and who did not. The second section is to show and describe any relationships among hypothesis-making, interpreting graphs, applying formulas, conclusion-making, conceptual understanding, and learning achievement. The last is to study students' perception and opinion of our developed app and activity designs.

\section{Analysis of Learning Effect}

We conducted a pre-test to see whether both groups are different or not in prior knowledge. The means and standard deviations of the pre-test scores for the experimental and control groups were 35.93 and 11.87 and 35.88 and 13.51 respectively. The results showed that no significant difference between both groups in prior knowledge $(t=0.77$ and $p=0.98)$. The results of post-test scores in Table 2 showed that experimental students outperformed than control students on learning achievement $(t=7.49$ and $\mathrm{p}<.001)$. It implied that the U-Physics app was beneficial for improving student learning achievement rather than a traditional stopwatch.

It showed that U-Physics was beneficial to students' learning. U-Physics can help students to learn simple pendulum because it uses a sensor of tablet PC to collect acceleration and velocity data during pendulum swinging (Purba \& Hwang, 2017a, 2017b). The accuracy of recording time based on pendulum acceleration and velocity more accurate than a stopwatch observing. Data collection was transformed into graphs synchronously by U-Physics. Therefore, students who use the U-Physics could understand the simple pendulum concept and solve related problems better than those students who used a stopwatch. In addition, U-Physics allowed students to annotate texts in their graphs. Text annotations represent students' understanding and reflection of what they learned. Text annotations could help students to interpret and understand the simple pendulum concepts in their own words. This finding indicated that text annotations have important roles in student learning achievement (Hwang, Chen, Shadiev, \& Li, 2011). Therefore, we suggest that teacher may encourage students to interpret more their findings by text annotations. The graphs and text annotations could facilitate students in exploring and applying their knowledge, intensely in a profoundly authentic problem (Golonka et al., 2014; Hwang et al., 2011; Purba \& Hwang, 2017a, 2017b).

Furthermore, the interview responses indicated that by experimenting with U-Physics app, most students did not only know the meaning of the simple pendulum formula but also understand the concepts and phenomena of a simple pendulum. It showed that U-Physics could facilitate students to know and understand more about simple pendulum problems. By practice simple pendulum phenomena in real experience, students use their skills repeatedly and regularly to improve and master them (Huffaker, 2004).

\section{Analysis of Relationship between Research Variables and Post-Test}

According to Table 3, the interpreting graphs positively correlated with applying formulas $(r=.391, p=.027)$, conclusion-making $(\mathrm{r}=.587, \mathrm{p}=.000)$, conceptual understanding $(\mathrm{r}=.615, \mathrm{p}=.000)$, and post-test $(\mathrm{r}=.450, \mathrm{p}=$. $010)$. The conceptual-understanding positively correlated with applying formulas $(r=.560, p=.001)$ and the hypothesis-making negatively correlated with the conclusions making ( $r=-.462, p=.008)$. 
Table 3. Pearson correlation between research variables and post-test in the experiment group

\begin{tabular}{|c|c|c|c|c|c|c|}
\hline & $\begin{array}{c}\text { Hypothesis } \\
\text { making }\end{array}$ & $\begin{array}{c}\text { Interpreting } \\
\text { graphs }\end{array}$ & $\begin{array}{l}\text { Applying } \\
\text { formulas }\end{array}$ & $\begin{array}{c}\text { Conclusion } \\
\text { making }\end{array}$ & $\begin{array}{c}\text { Conceptual } \\
\text { Under standing }\end{array}$ & $\begin{array}{l}\text { Post } \\
\text { test }\end{array}$ \\
\hline Hypothesis making & - & - & - & - & - & - \\
\hline Interpreting graphs & - & - & - & - & - & - \\
\hline \multirow[t]{2}{*}{ Conclusion making } & $-.462^{\star \star}$ & $.587^{* \star}$ & - & - & - & - \\
\hline & .008 & .000 & & & & \\
\hline \multirow[t]{2}{*}{ Applying formulas } & - & $.391^{\star}$ & - & - & - & - \\
\hline & & .027 & & & & \\
\hline \multirow[t]{2}{*}{ Conceptual Understanding } & - & $.615^{\star \star}$ & $.560^{\star *}$ & - & - & - \\
\hline & & .000 & .001 & & & \\
\hline \multirow[t]{2}{*}{ Posttest } & - & $.450^{\star \star}$ & - & - & $.762^{\star *}$ & - \\
\hline & & .010 & & & .000 & \\
\hline
\end{tabular}

The significant correlation between interpreting graphs and applying formulas implied that students who interpret the graphs correctly also tended to apply the correct formula. The interpreting graphs are a key to lead students to understand the simple pendulum concepts, so students need to pay more time and attention to it. Students could know how to apply and use the formula correctly when they have a good understanding of graphs. Students who interpret the graphs should understand where the data came from by integrating the formula. It means the students' ability to understand and work with graphs representations involves calculation processes (Friel et al., 2001).

The interpreting graphs correlated to conclusion-making illustrated that students who make a correct interpretation of graphs also make the correct conclusions. Students spent more time to understand and explain the graphs. The graphs represent the experimental result. Graphs understanding means understand experiment results; therefore, students conclude the experiment readily. Besides, the interpreting graphs could also be used to explain physics phenomena to students (Supalo et al., 2016; Zebehazy \& Wilton, 2014).

The correlation between interpreting graphs and conceptual understanding represented that students who are competent in interpreting graphs also are excellent in conceptual understanding. It is critical for students not only able to interpret the graphs, but also able to understand the simple pendulum concepts.

The interpreting graphs not only correlated to applying formulas, conclusion- making, and conceptual understanding but also correlated to learning achievement. It indicated that interpreting graphs play an important role in affecting other learning behaviors and learning achievement. It noted that students' mathematical pattern ability and explanation of the solution by verbal writing ability could help students' learning achievement. It also indicated that students' conceptual understanding could be promoted by allowing students to explore science phenomena with a computer or mobile app in their surroundings (Lee et al., 2004; McElhaney et al., 2015; Wang et al., 2017).

The significant correlation between applying formulas and conceptual understanding indicated that students who apply formula correctly also tended to have higher scores in conceptual understanding. By applying the formulas correctly and doing more practice, students' concepts and understandings about the formula also increase. Students not only know how to use the formula but also understand the meaning of the formula deeply at the end. It is consistent with Sherin (2001), the understanding of the formula can greatly surpass students' conceptual understanding. In addition, the same findings also found in interview responses. The following opinions are representative of those presented in the interviews.

"Yes, I knew the meaning of the formula and how to use it. It means the only length affect the period of the simple pendulum. The mass and the angle of the pendulum does not affect the period of the simple pendulum."

The significant correlation between conceptual understanding and learning achievement (post-test) indicated that students who understand the simple pendulum concepts correctly also tended to have higher scores in learning achievement. Regarding positive correlation results, the interpreting graphs and conceptual understanding became two most important factors to affect learning achievement in experiment group. Pearson correlation in the control group also showed that interpreting graphs more correlated to hypothesis making $(\mathrm{r}=.461, \mathrm{p}=.006)$, applying formulas $(r=-.618, p=.000)$, conclusion-making $(r=.830, p=.000)$, and learning achievement $(r=.358, p=.038)$. The results demonstrated that interpreting graphs had an important role in physics learning as well as conceptual understanding. It is consistent with the results of studies (Lingefjärd \& Farahani, 2017; Purba \& Hwang, 2017a, $2017 b$ ) which showed interpreting graphs could help improve better conceptual understanding. The knowledge of interpreting graphs can be very helpful in physics experiment and become an important step towards expertise in problem-solving (Beichner, 1994; Larkin \& Reif, 1979; Supalo et al., 2016; Zebehazy \& Wilton, 2014). In addition, 
Table 4. TAM questionnaire survey analysis

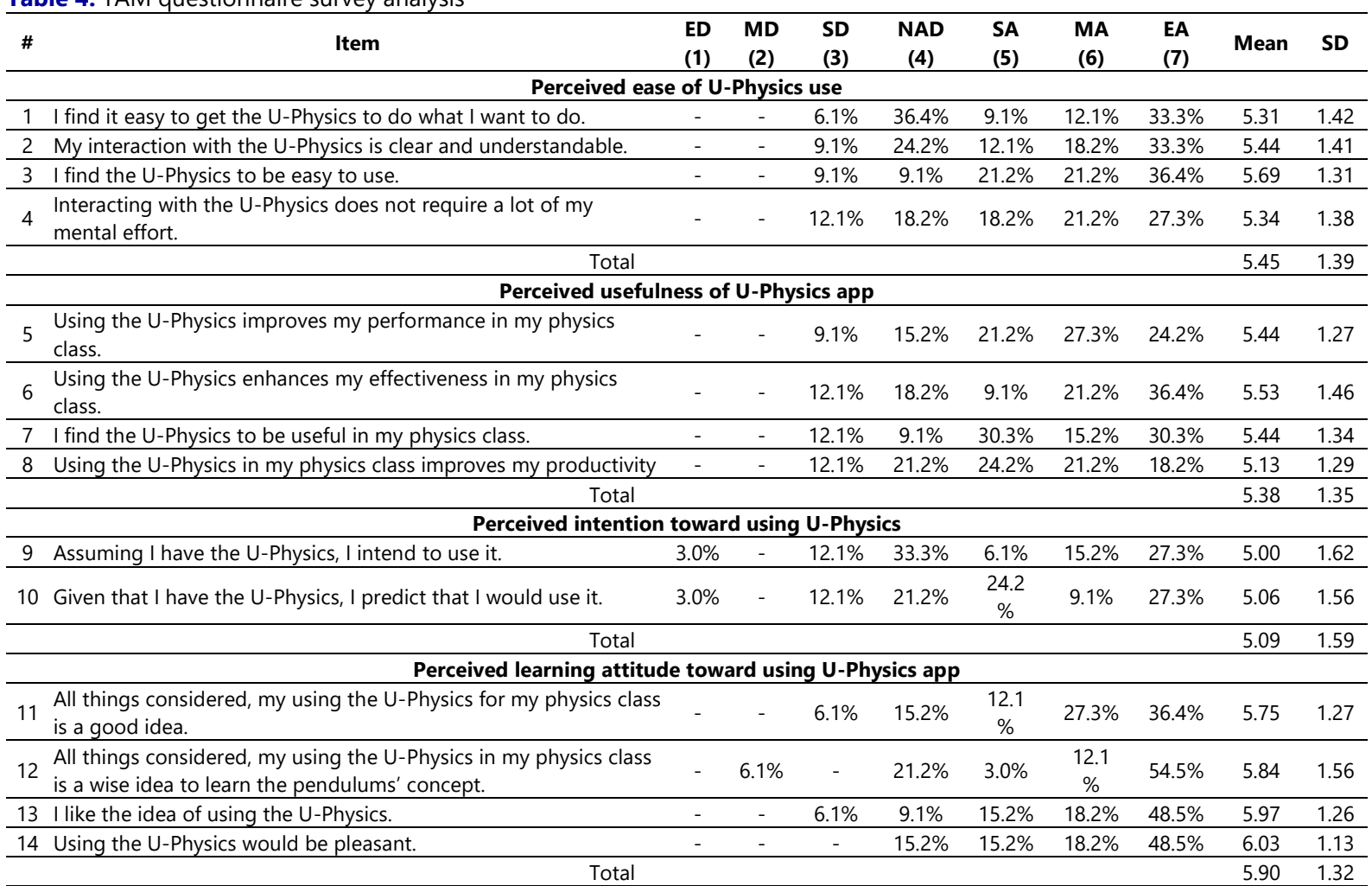

ED-Entirely Disagree; MD- Mostly Disagree; SD- Somewhat Disagree; NAD- Neither Agree nor Disagree; SA- Somewhat Agree; MA- Mostly Agree; EA- Entirely Agree

studies (Golonka et al., 2014; Purba \& Hwang, 2017a, 2017b) emphasized that interpreting graphs are one of the critical factors to affect students' learning. Furthermore, students' interview results showed that interpreting graphs are more important than others in learning physics because students spent more time for interpreting graphs. Students could not continue to the next steps if they did not finish interpreting graphs. The following opinions are representative of those presented in the interviews.

"I discussed and interacted with my peers during the interpreting graphs. I could not continue to others steps if my friend and I did not finish interpreting graphs."

"If I have different opinions of my peers during the interpreting graphs, I discussed again and asked teacher help."

Meanwhile, students' conceptual understanding increased when students interpreted their graphs correctly. So both interpreting and conceptual understanding are the key points to achieve a better learning achievement. Giving a daily life example (simple pendulum or swing) could also stimulate their motivation to learn physics. Therefore, physics teacher should tend to use graphs as a sort of the second language, assuming their students can extract most of their rich informational content and increase conceptual understanding.

The other finding is a significant negative correlation between hypothesis and conclusion making. It showed that students who make a hypothesis correctly tended to make the wrong conclusion. It may happen because students have less training after the experiment. Besides, it may also because female students have a lower selfconfidence level than male ones in science learning (Mullis \& Martin, 2008). Therefore, we suggest that teachers need to guide students how to conduct and make a better conclusion based on their findings. This phenomenon is interesting and worth further investigation in the future.

\section{Students' Perception of U-Physics}

The Table 4 shown the result of the questionnaire survey analysis. According to the results, most students' scores are high for the items of perceived learning attitude, perceived ease of U-Physics use, perceived of the usefulness of U-Physics app, and perceived intention toward using U-Physics.

The findings demonstrate that in general, students perceived that they are glad to use U-Physics and it was also easy for them to use. U-Physics was perceived useful for students during the experiment. We found that student 
learning attitude, ease of U-Physics use, and usefulness have high scores. Meanwhile, students' perception toward intention to U-Physics were the lowest. So we interviewed students to reveal the reasons behind the phenomenon. The interview result showed that an hour is not enough for them to repeat and do more practice during the experiment. Most students hope that they have more than an hour to learn physics and teacher will allow them to bring U-Physics back home. The following opinions are representative of those presented in the interviews.

"It is not enough. Maybe I need 2-3 hours in every week like science class usually."

"Yes, I will experiment if the teacher allowed me to bring U-Physics back home. Because I want to improve my study and I will show to my family or my brother so that we can learn together."

In terms of pedagogy, we recommend that interpreting graphs generated by U-Physics can facilitate students to find the critical variable of simple pendulums such as period and the length of the pendulum correctly and smoothly. The U-Physics also can help students to build their understanding of simple pendulum concepts. Besides, U-Physics is not just an excellent tool to measure the variable of simple pendulum accurately by providing graph rather than a traditional tool but also can link students' concept and experiment measurement in a laboratory. Therefore, we strongly suggest teachers and researchers should ask students to use graphs frequently in their physics phenomena solutions.

In terms of technical, we suggest that the acceleration sensor generated by U-Physics can collect the acceleration and velocity of the tablet during its swinging. The multi-representation such as graphs, text annotations, and many data integrated with U-Physics app can help teachers and teachers not only to build physics phenomena but also to organize and manipulate the sampling data for an in-depth analysis. Therefore, teachers and researchers should involve more representation skill in their teaching to help students learning as we did in U-Physics activities. In addition, teachers and researchers should design and utilize advanced features of mobile devices such as GPS, compass, acceleration, gyroscope, light, and gravity sensors for learning physics.

\section{CONCLUSION AND FURTHER STUDY}

The significant findings of both studies are outlined as follows. Firstly, significant positive correlations exist among hypothesis-making, interpreting graphs, applying formulas, conceptual understanding, and post-test. It indicated that the students' translation of verbal or vocal to mathematical pattern ability, transforming mathematical pattern into arithmetic symbol ability, and explanation of the solution by verbal writing ability can help student learning achievement. Particularly, interpreting graphs and conceptual understanding were the two most important factors to affect learning achievement. These two factors are key to continue others steps, so they need to spend more time to figure out the graphs and build their concept. Secondly, significant negative correlations exist between students' hypothesis-making and conclusion-making during activities. It indicated that a student who has low scores in hypothesis-making would get high scores in conclusion-making after the experiment, whereas a student who has high scores in hypothesis-making would get low scores in conclusion-making. It is because female students have a lower self-confidence level than male students ones in science learning (Mullis \& Martin, 2008). Lastly, most students' scores are high for the items of perceived learning attitude, perceived ease of U-Physics use, perceived of the usefulness of U-Physics app, and perceived intention toward using U-Physics. In addition, students in this current study are glad to use the U-Physics, and it was also easy for them to use. U-Physics has also perceived usefulness during the experiment.

However, we found several limitations of this study. First, duration of experiment activities is insufficient, so students did not intend to use U-Physics. Second, participants in this study only evolved vocational female which cannot generalize all the user content very well. It might affect the result. Therefore, in future, we would like to expand the duration of experiment activities and allow students to bring tablet PC at home. Students can use UPhysics after class anytime and anywhere. The future study also needs to consider the gender of participants.

\section{ACKNOWLEDGEMENT}

The authors would like to thank a teacher, Mr. Ma Zhao Heng for his assistance in performing the experiments.

\section{REFERENCES}

Ainsworth, S. (1999). The functions of multiple representations. Computers E Education, 33(2-3), $131-152$. https:/ / doi.org/10.1016/S0360-1315(99)00029-9

Beichner, R. J. (1994). Testing student interpretation of kinematics graphs. American Journal of Physics, 62(8), 750762. https:// doi.org/10.1119/1.17449 
Cai, J., \& Hwang, S. (2002). Generalized and generative thinking in US and Chinese students' mathematical problem solving and problem posing. The Journal of Mathematical Behavior, 21(4), 401-421. https:/ / doi.org/10.1016/S0732-3123(02)00142-6

Chung, J., \& Tan, F. B. (2004). Antecedents of perceived playfulness: an exploratory study on user acceptance of general information-searching websites. Information $\mathcal{E}$ Management, 41(7), 869-881. https:// doi.org/10.1016/j.im.2003.08.016

Dabbagh, N., \& Kitsantas, A. (2012). Personal Learning Environments, social media, and self-regulated learning: A natural formula for connecting formal and informal learning. The Internet and Higher Education, 15(1), 3-8. https:// doi.org/10.1016/j.iheduc.2011.06.002

De Jong, T. (2006). Scaffolds for scientific discovery learning. Handling complexity in learning environments: Theory and research, 107-128.

DeWindt-King, A., \& Goldin, G. (2003). Children's visual imagery: Aspects of cognitive representation in solving problems with fractions. Mediterranean Journal for Research in Mathematics Education, 2(1), 1-42.

Duschl, R. A., \& Gitomer, D. H. (1991). Epistemological perspectives on conceptual change: Implications for educational practice. Journal of research in science teaching, 28(9), 839-858. https://doi.org/10.1002/tea.3660280909

Dykstra, D. I., Boyle, C. F., \& Monarch, I. A. (1992). Studying conceptual change in learning physics. Science Education, 76(6), 615-652. https://doi.org/10.1002/sce.3730760605

Etkina, E., Murthy, S., \& Zou, X. (2006). Using introductory labs to engage students in experimental design. American journal of Physics, 74(11), 979-986. https:/ / doi.org/10.1119/1.2238885

Fortus, D. (2009). The importance of learning to make assumptions. Science Education, 93(1), 86-108. https://doi.org/10.1002/sce.20295

Friel, S. N., Curcio, F. R., \& Bright, G. W. (2001). Making sense of graphs: Critical factors influencing comprehension and instructional implications. Journal for Research in mathematics Education, 124-158. https://doi.org/10.2307/749671

Golonka, E. M., Bowles, A. R., Frank, V. M., Richardson, D. L., \& Freynik, S. (2014). Technologies for foreign language learning: a review of technology types and their effectiveness. Computer assisted language learning, 27(1), 70-105. https:/ / doi.org/10.1080/09588221.2012.700315

Greca, I. M., \& de Ataíde, A. R. P. (2017). The Influence of Epistemic ViewsEpistemic views About the Relationship between Physics and Mathematics in Understanding Physics Concepts and Problem Solving. Key Competences in Physics Teaching and Learning (pp. 55-64): Springer.

Huffaker, D. (2004). Spinning yarns around the digital fire: Storytelling and dialogue among youth on the Internet. First Monday, 9(1). https:/ / doi.org/10.5210/fm.v9i1.1110

Hwang, W. Y., Chen, N. S., Shadiev, R., \& Li, J. S. (2011). Effects of reviewing annotations and homework solutions on math learning achievement. British Journal of Educational Technology, 42(6), 1016-1028. https://doi.org/10.1111/j.1467-8535.2010.01126.x

Hwang, W.-Y., Chen, H. S., Shadiev, R., Huang, R. Y.-M., \& Chen, C.-Y. (2014). Improving English as a foreign language writing in elementary schools using mobile devices in familiar situational contexts. Computer assisted language learning, 27(5), 359-378. https:/ / doi.org/10.1080/09588221.2012.733711

Hwang, W.-Y., Chen, N.-S., Dung, J.-J., \& Yang, Y.-L. (2007). Multiple Representation Skills and Creativity Effects on Mathematical Problem Solving using a Multimedia Whiteboard System. Journal of Educational Technology $\mathcal{E}$ Society, 10(2).

Hwang, W.-Y., Huang, Y.-M., Shadiev, R., Wu, S.-Y., \& Chen, S.-L. (2014). Effects of using mobile devices on English listening diversity and speaking for EFL elementary students. Australasian journal of educational technology, 30(5). https:// doi.org/10.14742/ajet.237

Kalyuga, S., Chandler, P., \& Sweller, J. (2000). Incorporating learner experience into the design of multimedia instruction. Journal of educational psychology, 92(1), 126. https:/ / doi.org/10.1037/0022-0663.92.1.126

Kiernan, P. J., \& Aizawa, K. (2004). Cell phones in task based learning-Are cell phones useful language learning tools? ReCALL, 16(1), 71-84. https:/ / doi.org/10.1017/S0958344004000618

Kim, P., Suh, E., \& Song, D. (2015). Development of a design-based learning curriculum through design-based research for a technology-enabled science classroom. Educational Technology Research and Development, 63(4), 575-602. https:// doi.org/10.1007/s11423-015-9376-7

Kim, S.-y., \& Kim, M.-r. (2012). Kolb's learning styles and educational outcome: Using Digital Mind Map as a study tool in Elementary English class. International Journal for Educational Media and Technology, 6(1), 4-13. 
Klahr, D., \& Dunbar, K. (1988). Dual space search during scientific reasoning. Cognitive science, 12(1), 1-48. https://doi.org/10.1207/s15516709cog1201_1

Kohl, P. B., Rosengrant, D., \& Finkelstein, N. D. (2007). Strongly and weakly directed approaches to teaching multiple representation use in physics. Physical Review Special Topics-Physics Education Research, 3(1), 010108. https:/ / doi.org/10.1103/PhysRevSTPER.3.010108

Larkin, J. H., \& Reif, F. (1979). Understanding and teaching problem-solving in physics. European journal of science education, 1(2), 191-203. https:/ / doi.org/10.1080/0140528790010208

Lee, K. M., Nicoll, G., \& Brooks, D. W. (2004). A comparison of inquiry and worked example web-based instruction using physlets. Journal of Science Education and Technology, 13(1), 81-88. https:// doi.org/10.1023/B:JOST.0000019640.07432.2b

Lesh, R., Post, T., \& Behr, M. (1987). Representations and translations among representations in mathematics learning and problem solving. Problems of representation in the teaching and learning of mathematics, 21, 33-40.

Leslie, K. C., Low, R., Jin, P., \& Sweller, J. (2012). Redundancy and expertise reversal effects when using educational technology to learn primary school science. Educational Technology Research and Development, 60(1), 1-13. https:// doi.org/10.1007/s11423-011-9199-0

Lin, T.-J., Liang, J.-C., \& Tsai, C.-C. (2015). Identifying Taiwanese university students' physics learning profiles and their role in physics learning self-efficacy. Research in Science Education, 45(4), 605-624. https:// doi.org/10.1007/s11165-014-9440-z

Lingefjärd, T., \& Farahani, D. (2017). The Elusive Slope. International Journal of Science and Mathematics Education, 120. https:/ / doi.org/10.1007/s10763-017-9811-9

Mayer, R. E. (1992). Thinking, problem solving, cognition: WH Freeman/Times Books/Henry Holt \& Co.

McElhaney, K. W., Chang, H.-Y., Chiu, J. L., \& Linn, M. C. (2015). Evidence for effective uses of dynamic visualisations in science curriculum materials. Studies in Science Education, 51(1), 49-85. https://doi.org/10.1080/03057267.2014.984506

McKenzie, D. L., \& Padilla, M. J. (1986). The construction and validation of the test of graphing in science (TOGS). Journal of research in science teaching, 23(7), 571-579. https:/ / doi.org/10.1002/ tea.3660230702

McLeod, J. D., \& Kaiser, K. (2004). Childhood emotional and behavioral problems and educational attainment. American sociological review, 69(5), 636-658. https:/ / doi.org/10.1177/000312240406900502

Milrad, M. (2002). Using construction kits, modeling tools and system dynamics simulations to support collaborative discovery learning. Educational Technology E Society, 5(4), 76-87.

Mullis, I. V., \& Martin, M. O. (2008). Overview of TIMSS 2007. Chestnut Hill, MA: TIMSS E PIRLS.

Nievelstein, F., Van Gog, T., Van Dijck, G., \& Boshuizen, H. P. (2013). The worked example and expertise reversal effect in less structured tasks: Learning to reason about legal cases. Contemporary Educational Psychology, 38(2), 118-125. https:/ / doi.org/10.1016/j.cedpsych.2012.12.004

Nishida, H. (2005). Cultural schema theory. Theorizing about intercultural communication, 401418.

Posner, G. J., Strike, K. A., Hewson, P. W., \& Gertzog, W. A. (1982). Accommodation of a scientific conception: Toward a theory of conceptual change. Science Education, 66(2), 211-227. https:// doi.org/10.1002/sce.3730660207

Purba, S. W. D., \& Hwang, W.-Y. (2017a). Investigation of Learning Behaviors and Achievement of Vocational High School Students Using an Ubiquitous Physics Tablet PC App. Journal of Science Education and Technology, 26(3), 322-331. https:/ / doi.org/10.1007/s10956-016-9681-x

Purba, S. W. D., \& Hwang, W.-Y. (2017b). Investigation of Learning Behaviors and Their Effects to Learning Achievement Using Ubiquitous-Physics App. Paper presented at the Advanced Learning Technologies (ICALT), 2017 IEEE 17th International Conference on. https:/ / doi.org/10.1109/ICALT.2017.10

Sherin, B. L. (2001). How students understand physics equations. Cognition and instruction, 19(4), 479-541. https://doi.org/10.1207/S1532690XCI1904_3

Stylianou, D. A., \& Silver, E. A. (2004). The role of visual representations in advanced mathematical problem solving: An examination of expert-novice similarities and differences. Mathematical thinking and learning, 6(4), 353-387. https://doi.org/10.1207/s15327833mt10604_1

Sullivan, S. A., \& Puntambekar, S. (2015). Learning with digital texts: Exploring the impact of prior domain knowledge and reading comprehension ability on navigation and learning outcomes. Computers in Human Behavior, 50, 299-313. https:/ / doi.org/10.1016/j.chb.2015.04.016 
Supalo, C. A., Humphrey, J. R., Mallouk, T. E., Wohlers, H. D., \& Carlsen, W. S. (2016). Examining the use of adaptive technologies to increase the hands-on participation of students with blindness or low vision in secondary-school chemistry and physics. Chemistry Education Research and Practice, 17(4), 1174-1189. https://doi.org/10.1039/C6RP00141F

Wang, J.-Y., Wu, H.-K., \& Hsu, Y.-S. (2017). Using mobile applications for learning: Effects of simulation design, visual-motor integration, and spatial ability on high school students' conceptual understanding. Computers in Human Behavior, 66, 103-113. https: / / doi.org/10.1016/j.chb.2016.09.032

Zebehazy, K. T., \& Wilton, A. P. (2014). Straight from the Source: Perceptions of Students with Visual Impairments about Graphic Use. Journal of Visual Impairment \& Blindness, 108(4), 275-286.

Zhang, J. (1997). The nature of external representations in problem solving. Cognitive science, 21(2), $179-217$. https://doi.org/10.1207/s15516709cog2102_3

\section{http://www.ejmste.com}

